\title{
IMPLEMENTATION OF COOPERATIVE LEARNING MODEL TYPE MAKE A MATCH TO IMPROVE CONCEPTS COMPREHENSION OF TWO DIMENTIONAL FIGURE CHARACTER
}

\section{Santri Prabowo Utomo, Sukarno, Muhammad Ismail Sriyanto}

Universitas Sebelas Maret

santriprabowoutomo@gmail.com

\section{Article History}

accepted 09/07/2018

approved 01/08/2018

published 17/09/2018

\section{Keywords}

Concepts comprehension, two dimentional figure character, Make a Match

\begin{abstract}
The purpose of this research is to improve concepts comprehension two dimentional figure character through the implementation of cooperative learning model type Make a Match. The source of the data comes from teachers, students, and researches. The data collection technique is by test, interview, observation, and documentation. The validity of the data used content validity and data triangulation. The data analysis used interactive data analysis by Miles and Huberman (2014) which consist of data reduction, data presentation, and conclusion. The results of this research is the average scores that students classical mastery cycle I and cycle II increased. The average scores is 87,5 in cycle II with students classical mastery $88,89 \%$ or 16 students of 18 students is completed. The conclusion of this research is through the implementation of cooperative learning model type Make a Match can improve concepts comprehension mathematics leaning about two dimentional figure character.
\end{abstract}

Social, Humanities, and Education Studies (SHEs): Conference Series

p-ISSN 2620-9284 https://jurnal.uns.ac.id/shes e-ISSN 2620-9292 


\section{PENDAHULUAN}

Pembelajaran terjadi di mana saja, kapan saja, dan sepanjang masa. Proses pembentukan diri atau perubahan pada seorang peserta didik untuk menjadi manusia seutuhnya terjadi di dalam sebuah pembelajaran. Salah satu ilmu dasar dalam sebuah pembelajaran di Sekolah Dasar adalah Matematika. Menurut Hendriana (2014) Matematika adalah sebagai salah satu ilmu dasar atau acuan, baik dari aspek terapannya ataupun penalaran logisnya yang mempunyai peranan penting dalam upaya mengembangkan penguasaan ilmu dan teknologi serta digunakan sebagai bekal untuk memecahkan masalah pada kehidupan sehari-hari. Untuk itu, matematika di sekolah dasar perlu diupayakan pembelajarannya sebagai sarana agar dapat menumbuhkembangkan kecerdasan, pemahaman, kemampuan, serta keterampilan untuk membentuk kepribadian yang baik pada peserta didik. Matematika mempunyai ciri-ciri yang objeknya bersifat abstrak dengan pola pikir yang konsisten dan bersifat universal secara global. Oleh karena itu, pendidik harus lebih banyak berperan sebagai pembimbing daripada sebagai pemberi tahu.

Matematika sering sekali dianggap sebagai pelajaran yang sangat sulit dan menakutkan bagi siapapun, termasuk anak yang masih duduk di bangku Sekolah Dasar. Angggapan tersebut membuat mereka menjadi malas belajar, tidak senang, menjadi beban yang berat, dan takut untuk belajar matematika sehingga berakibat kepada prestasi belajar matematika yang menjadi kurang maksimal, baik mengenai pengetahuan, sikap, maupun keterampilan. Maka dari itu perlu ditanamkan pemahaman mengenai konsep-konsep yang menjadi dasar acuan pembelajaran tersebut. Santrock (2011) mengungkapkan bahwa pemahaman konsep adalah pondasi berpikir mengenai pengetahuan siswa dalam kategori mengelompokkan objek, ilmu, dan pengetahuan berdasarkan pengalaman langsung dengan objek atau kejadian dalam dunia mereka yang diperolehnya untuk membantu proses mengingat menjadi lebih efisien, sederhana, jelas, dan konkret. Erladini (2017) mengungkapkan bahwa dengan memahami konsep, siswa ke depannya dapat mengaplikasikan konsep di kehidupan sehari-harinya, hal ini dapat membimbing siswa mendapatkan tujuan dari kegiatan pembelajaran yang diikuti tersebut

Hasil dari ulangan pratindakan yang telah dilaksanakan, diperoleh penjelasan data sebagai berikut: 1) nomor soal dengan jumlah siswa terendah yang dapat menjawab adalah mengenai besar sudut pada segitiga sama kaki yaitu 3 siswa; 2) nomor soal dengan jumlah siswa tertinggi yang dapat menjawab adalah mengenai bentuk bangun persegi dan bangun layang-layang yaitu 18 siswa; 3) nilai terendah dalam kelas yaitu 20; 4) nilai tertinggi dalam kelas yaitu 70;3) rata-rata kelas sebesar 41,14 ; dan 4) persentase ketuntasan siswa sebesar $22,22 \%$ atau 4 siswa yang tuntas, dan $77,78 \%$ atau 14 siswa belum tuntas.

Berdasarkan hasil data pratidakan di atas, apabila permasalahan yang terjadi tidak segera diatasi akan berdampak buruk bagi siswa, terutama dalam menguasai materi pembelajaran. Sebagai usaha untuk memecahkan masalah tersebut, dengan cara mengajak siswa untuk bermain karena pada dasarnya anak-anak itu masih suka untuk bermain. Pembelajaran yang menyenangkan untuk peserta didik adalah mereka terlibat secara aktif dalam pembelajaran sehingga pembelajaran tidak terkesan membosankan untuk dipelajari dan siswa dapat memahami materi yang telah diajarkan. Berkaitan dengan pembelajaran matematika, diperlukan model pembelajaran yang aktif, kreatif, efektif, menyenangkan, dan inovatif untuk dapat memudahkan siswa menerima materi, memotivasi siswa, dan meningkatkan pemahaman konsep siswa tentang sifat-sifat bangun datar. Model pembelajaran yang akan digunakan ini disesuaikan dengan siswa yang masih suka bermain, maka dari itu peneliti akan menerapkan model pembelajaran Kooperatif tipe Make a Match atau permainan mencari kartu pasangan pada materi sifat-sifat bangun datar. 
Model pembelajaran Kooperatif tipe Make a Match ini dikembangkan pertama kali oleh seorang ahli bernama Lorna Cuman pada tahun 1994. Model pembelajaran ini mengajak siswa untuk mencari pasangan yang cocok dari kartu yang telah dipersiapkan oleh guru. Kartu-kartu ini berisi pertanyaan maupun jawaban yang saling berkaitan. Huda (2011) berpendapat bahwa model pembelajaran ini berupa sebuah permainan yang dilakukan siswa untuk mencari pasangan sambil belajar suatu konsep pemahaman dan topik pembelajaran dalam suasana bermain yang menyenangkan serta dapat diterapkan untuk semua mata pelajaran dan tingkatan kelas. Sejalan dengan pendapat ahli tersebut, Suprijono (2009) mengungkapkan bahwa model pembelajaran Kooperatif tipe Make a Match ini merupakan model pembelajaran yang dikembangkan melalui sebuah permainan mencari kartu pasangan yang berisi kartukartu tentang pertanyaan dan kartu-kartu tentang jawaban yang saling berkaitan.

Suatu model pembelajaran pasti memiliki kelebihan dan kekurangan. Lie (2005) menjelaskan mengenai kelebihan dan kekurangan kelompok berpasangan dalam model pembelajaran Kooperatif tipe Make a Match ini. Kelebihan model pembelajaran ini yaitu: a) meningkatkan partisipasi antar anggota kelompok; b) cocok untuk tugas sederhana; c) lebih banyak kesempatan siswa berkontribusi pada masing-masing kelompoknya; d) interaksi menjadi lebih mudah dan cepat membentuknya karena langsung terjadi. Sedangkan kekurangan model pembelajaran ini yaitu: a) banyak siswa yang perlu diamati dan perlu dimonitor; b) lebih sedikit ide yang muncul.

Berdasarkan uraian permasalahan di atas, untuk meningkatkan pemahaman konsep mengenai sifat-sifat bangun datar, maka peneliti bermaksud mengadakan Penelitian Tindakan Kelas (PTK) dengan judul: "Peningkatan Pemahaman Konsep Sifat-Sifat Bangun Datar Melalui Model Pembelajaran Make a Match Pada Siswa Kelas V SD Negeri 02 Bendosari Boyolali Tahun Ajaran 2017/2018".

\section{METODE}

Penelitian ini berupa Penelitian Tindakan Kelas (PTK). Penelitian dilaksanakan dua siklus yang terdiri perencanaan, tindakan, observasi, dan refleksi. Subjek penelitian adalah guru dan siswa kelas $\mathrm{V}$ berjumlah 18 siswa, terdiri 11 siswa laki-laki dan 7 siswa perempuan.

Data kualitatif berupa hasil wawancara guru dan siswa kelas $\mathrm{V}$ serta hasil observasi aktivitas siswa dan kinerja guru. Data kuantitatif didapat dari hasil nilai pemahaman konsep mengenai sifat-sifat bangun datar. Data didapat sebelum dan sesudah penerapan model pembelajaran Kooperatif tipe Make a Match.

Sumber data primer berupa hasil tes pemahaman konsep pratindakan, siklus I, dan Siklus II mengenai sifat-sifat bangun datar, hasil wawancara guru dan siswa serta hasil observasi aktivitas siswa dan kinerja guru. Sumber data sekunder berasal dari dokumen Standar Kompetensi dan Kompetensi Dasar semester II, silabus dan Rencana Pelaksanaan Pembelajaran (RPP) matematika kelas V, serta foto dan video.

Teknik pengumpulan data yang digunakan adalah observasi, wawancara, tes, dan dokumentasi. Teknik uji validitas data menggunakan validitas isi, triangulasi sumber, dan triangulasi teknik. Teknik analisis data yang digunakan adalah model analisis data interaktif oleh Miles and Huberman dalam (Sugiyono, 2015) terdiri dari reduksi data, penyajian data, dan pengambilan kesimpulan.

\section{HASIL DAN PEMBAHASAN}

Pada kondisi awal pratindakan, diperoleh data hasil nilai pemahaman konsep. Data yang telah diperoleh mengenai rata-rata nilai pemahaman konsep matematika tentang sifat-sifat bangun datar di kelas V SD Negeri 02 Bendosari Boyolali tahun ajaran 2017/2018 dari 18 siswa hanya 4 siswa atau 22.22\% yang mencapai nilai KKM. 
Dengan demikian, maka peneliti menyimpulkan bahwa pemahaman konsep matematika tentang sifat-sifat bangun datar pada siswa kelas V SD Negeri 02 Bendosari Boyolali masih tergolong rendah. Data distribusi frekuensi nilai tes pratindakan disajikan pada tabel sebagai berikut:

Tabel 1: Distribusi Frekuensi Nilai Pratindakan

\begin{tabular}{|c|c|c|c|c|c|}
\hline No & Interval Nilai & Frekuensi & Nilai Tengah & fi.xi & Persentase \\
\hline 1 & $20-28$ & 1 & 24 & 24 & $5,56 \%$ \\
\hline 2 & $29-37$ & 9 & 33 & 297 & $50 \%$ \\
\hline 3 & $38-46$ & 3 & 42 & 126 & $16,67 \%$ \\
\hline 4 & $47-55$ & 1 & 51 & 51 & $5,56 \%$ \\
\hline 5 & $56-64$ & 0 & 60 & 0 & $0 \%$ \\
\hline \multirow[t]{2}{*}{6} & $65-73$ & 4 & 69 & 276 & $22,21 \%$ \\
\hline & Jumlah & 18 & & 774 & $100 \%$ \\
\hline \multicolumn{4}{|c|}{ Nilai Terendah } & \multicolumn{2}{|c|}{20} \\
\hline \multicolumn{4}{|c|}{ Nilai Tertinggi } & \multicolumn{2}{|c|}{70} \\
\hline \multicolumn{4}{|c|}{ Nilai Rata-rata Kelas } & \multicolumn{2}{|c|}{41,11} \\
\hline \multicolumn{4}{|c|}{ Persentase Ketuntasan } & \multicolumn{2}{|c|}{$22,22 \%$} \\
\hline
\end{tabular}

Pada Tabel 1 di atas menunjukkan bahwa nilai rata-rata kelas yang dicapai oleh siswa pada pratindakan adalah 41,11, nilai terendah yaitu 20 dan nilai tertinggi yaitu 70 dengan persentase ketuntasan klasikal sebesar $22,22 \%$. Hal ini didukung dengan data hasil observasi kinerja guru sebesar 1,92 dengan kategori cukup dan aktivitas siswa sebesar 1,77 dengan kategori cukup. Data yang telah disajikan di atas selanjutnya digunakan oleh peneliti untuk menyusun rencana pelaksanaan penelitian guna memecahkan permasalahan di kelas V SD Negeri 02 Bendosari Boyolali.

Pelaksanakan serangkaian kegiatan pembelajaran pada siklus I dengan penerapan model pembelajaran Kooperatif tipe Make a Match. Berikut ini disajikan data distribusi frekuensi nilai pemahaman konsep sifat-sifat bangun datar siswa kelas $\mathrm{V}$ pada siklus I dalam bentuk tabel yaitu:

Tabel 2: Distribusi Frekuensi Siklus I

\begin{tabular}{cccccc}
\hline No & Interval Nilai & Frekuensi & Nilai Tengah & fi.xi & Persentase \\
\hline 1 & $59-65$ & 2 & 62 & 124 & $11,11 \%$ \\
2 & $66-72$ & 2 & 69 & 138 & $11,11 \%$ \\
3 & $73-79$ & 4 & 76 & 304 & $22,22 \%$ \\
4 & $80-86$ & 4 & 83 & 332 & $22,22 \%$ \\
5 & $87-93$ & 1 & 90 & 90 & $5,56 \%$ \\
6 & $94-100$ & 5 & 97 & 485 & $27,78 \%$ \\
& Jumlah & $\mathbf{1 8}$ & & $\mathbf{1 4 7 3}$ & $\mathbf{1 0 0 \%}$ \\
Nilai Terendah & & & \multicolumn{2}{c}{$\mathbf{6 0}$} \\
Nilai Tertinggi & & \multicolumn{2}{c}{$\mathbf{8 1 , 3 9}$} \\
Nilai Rata-rata Kelas & & \multicolumn{2}{c}{$\mathbf{5 5 , 5 6 \%}$} \\
Persentase Ketuntasan & &
\end{tabular}

Sajian pada Tabel 2 di atas menunjukkan bahwa nilai rata-rata kelas pada siklus I meningkat menjadi 81,11 , nilai terendah yaitu 60 dan nilai tertinggi yaitu 100 dengan ketuntasan klasikal yang juga mengalami peningkatan menjadi $61,11 \%$. Hasil tersebut menunjukkan bahwa pembelajaran sudah berlangsung lebih baik daripada sebelumnya. Hal ini didukung dengan data yang meningkat pada hasil observasi kinerja guru sebesar 3,04 dengan kategori sangat baik dan aktivitas siswa sebesar 2,65. Meski demikian, indikator kinerja penelitian yang dilihat melalui ketuntasan klasikal, yaitu sebesar $\geq 85 \%$ pada siklus I ini belum terpenuhi. Oleh karena itu, peneliti 
bekerja sama dengan guru kelas V SD Negeri 02 Bendosari Boyolali berupaya untuk melakukan perbaikan dan melanjutkan tindakan pada siklus II.

Pelaksanakan serangkaian kegiatan pembelajaran pada siklus II dengan penerapan model pembelajaran Kooperatif tipe Make a Match dalam rangka perbaikan dari siklus I. Diperoleh hasil data pada siklus II terjadi peningkatan yang cukup signifikan pula dibandingkan dengan siklus I. Data distribusi frekuensi nilai pemahaman konsep sifat-sifat bangun datar pada siklus II secara rinci disajikan pada tabel berikut:

Tabel 3 Distribusi Frekuensi Siklus II

\begin{tabular}{cccccc}
\hline No & Interval Nilai & Frekuensi & Nilai Tengah & fi.xi & Persentase \\
\hline 1 & $65-70$ & 1 & 67,5 & 67,5 & $5,56 \%$ \\
2 & $71-76$ & 1 & 73,5 & 73,5 & $5,56 \%$ \\
3 & $77-82$ & 5 & 79,5 & 397,5 & $27,78 \%$ \\
4 & $83-88$ & 4 & 85,5 & 342 & $22,22 \%$ \\
5 & $89-94$ & 0 & 91,5 & 0 & $0 \%$ \\
6 & $95-100$ & 7 & 97,5 & 682,5 & $38,89 \%$ \\
\multicolumn{1}{l}{ Jumlah } & $\mathbf{1 8}$ & & $\mathbf{1 5 6 3}$ & $\mathbf{1 0 0 \%}$ \\
Nilai Terendah & & & \multicolumn{2}{c}{$\mathbf{6 5}$} \\
Nilai Tertinggi & & \multicolumn{3}{c}{$\mathbf{1 0 0}$} \\
Nilai Rata-rata Kelas & & \multicolumn{2}{c}{$\mathbf{8 7 , 5}$} \\
Persentase Ketuntasan & &
\end{tabular}

Berdasarkan Tabel 3 di atas, tampak nilai rata-rata kelas meningkat dari siklus sebelumya, yakni menjadi 87,5 , nilai terendah yaitu 65 dan nilai tertinggi yaitu 100 dengan ketuntasan klasikal yang mengalami peningkatan menjadi $88,89 \%$. Hal ini didukung dengan peningkatan pada hasil kinerja guru sebesar 3,63 dengan kategori sangat baik dan aktivitas siswa sebesar 3,38 dengan kategori sangat baik. Hasil siklus II tersebut menunjukkan bahwa upaya perbaikan terhadap kekurangan-kekurangan yang terdapat pada siklus I sebelumnya dapat dikatakan berhasil. Pencapaian yang diperoleh pada siklus II menunjukkan bahwa indikator kinerja penelitian telah terpenuhi, sehingga penelitian diakhiri hanya sampai pada siklus II saja.

Sebuah tujuan dalam pembelajaran berguna untuk memberikan pengetahuan baru kepada siswa. Sagala (2014) mengungkapkan bahwa pemahaman konsep adalah buah hasil pemikiran seseorang yang diperoleh berdasarkan fakta, peristiwa, dan pengalamannya yang bersifat abstrak menjadi dasar pengetahuan yang disepakati bersama dan dapat mengalami perubahan yang disesuaikan dengan fakta maupun pengetahuan baru.Dengan mempelajari konsep ini, siswa dapat memahami mengenai sifat-sifat bangun datar yang bermacam-macamSebuah gambaran atau visualisasi yang diajarkan pada guru ini akan lebih mudah dalam menanamkan konsep pada siswa karena siswa melihat pada objek yang nyata dalam pembelajaran. Mulai dari mereka yang belum mengerti menjadi mengerti, dari paham menjadi paham, dan dari belum bisa menjadi bisa ini dinamakan perubahan berupa pengetahuan yang terjadi setelah siswa memahami sebuah konsep.

Peningkatan pemahaman konsep sifat-sifat bangun datar salah satunya didukung dengan diterapkannya model pembelajaran Kooperatif tipe Make a Match sebagai hasil dari refleksi pratindakan yang berupa permainan mencari pasangan antara kartu pertanyaan dan kartu jawaban. Permainan mencari kartu pasangan ini membuat siswa lebih aktif dan bergerak untuk mencari pasangan masing-masing kartu yang dipegang. Hasil dari refleksi siklus I, pada siklus II kartu pasangan ini dibuat lebih berwarna agar siswa lebih termotivasi dan menarik untuk mengikuti permainan, dapat menghidupkan suasana pembelajaran sehingga pembelajaran menjadi menyenangkan dan menarik. Permainan mencari kartu pasangan ini mengajak siswa untuk belajar sambil bermain dengan senang. 
Lestari (2015) mengungkapkan bahwa model pembelajaran Kooperatif tipe Make a Match ini adalah model pembelajaran yang digunakan untuk memberikan suatu konsep pemahaman materi yang sulit kepada siswa melalui sebuah permainan serta dapat digunakan untuk mengetahui sejauh mana tingkat pengetahuan dan kemampuan siswa dalam pembelajaran. Aini (2016) berpendapat bahwa Model Make a Match ini meminta siswa mencari pasangan kartu pertanyaan dan kartu soal sebelum waktu habis agar siswa tidak merasa bosan saat kegiatan pembelajaran berlangsung Fidiyanti (2017) mengungkapkan penerapan model pembelajaran ini juga dapat meningkatkan kegiatan pembelajaran siswa tentang pengetahuan dan interaksi fisiknya karena model ini membutuhkan keaktifan siswa untuk mencari pasangan sehingga siswa dapat belajar memahami konsep dalam lingkungan pembelajaran yang menyenangkan.

\section{SIMPULAN}

Berdasarkan hasil analisi data dan pembahasan di atas, dapat disimpulkan bahwa dalam penelitian mengenai peningkatan pemahaman konsep pembelajaran matematika sifat-sifat bangun datar melalui penerapan model pembelajaran Kooperatif tipe Make a Match dinyatakan telah berhasil dan terbukti dapat meningkatkan nilai siswa kelas V SD Negeri 02 Bendosari Boyolali tahun ajaran 2017/2018.

Berkaitan dengan hasil penelitian tindakan kelas di atas, pemberian tindakan pada penelitian ini dapat memberikan gambaran bahwa dengan penerapan model pembelajaran Kooperatif tipe Make a Match dalam meningkatkan pemahaman konsep sifat-sifat bangun datar ini terbukti berhasil. Peningkatan ini juga didukung dengan hasil observasi kinerja guru dan aktivitas siswa yang juga meningkat.

\section{DAFTAR PUSTAKA}

Aini, N. (2016). The Impelementation Of Cooperative Learning By Using Jigsaw And Make A Match Method To Improve The Activity And Learning Outcomes Of Social Science. Proceeding The $2^{\text {nd }}$ International Conference On Teacher Training And Education Sebelas Maret University (E-Journal), 2 (1), 284-289. ISSN: 25002-4124.

Fidiyanti, N. (2017). Effect Of Implementatin Of Cooperative Learning Model Make A Match Technique On Student Learning Motivation In Social Science Learning. International Journal Pedagogy Of Social Studies (e-Journal), 2 (1), 1-6. Diperoleh pada 1 Maret 2018, dari http://ejournal.upi.edu/index.php/pips/article/view/8667/5573.

Erladini, Y. C. (2017) Effectiveness About Techniques Of Puzzle Games In Understanding The Concept When Learning Social Science At Junior High School Of 40 Bandung. International Journal Pedagogy Of Social Studies (eJournal), 2 (2), 63-66. Diperoleh pada 1 Maret 2018, dari http://ejournal.upi.edu/index.php/pips/article/view/10167/6295.

Hendriana, H. \& Utari S. (2014). Penilaian Pembelajaran Matematika. Bandung: Refika Aditama.

Huda, M. (2011). Cooperative Learning Metode, Teknik, Struktur dan Model Terapan. Yogyakarta: Pustaka Pelajar.

Lestari, K. E. dan Mokhammad R. Y. (2015). Penelitian Pendidikan Matematika. Bandung: Refika Aditama.

Lie, A. (2005). Cooperative Learning (Mempraktikkan Cooperative Learning Di RuangRuang Kelas. Jakarta: Grasindo

Suprijono, A. (2009). Coorperative Learning Teori dan Aplikasi PAIKEM. Yogyakarta: Pustaka pelajar. 